\title{
A Quality Discriminaton within Ultra Violet Spectrum using Optical Sensor for Selected Commercial Oils
}

\author{
Khadijah Ismail ${ }^{1, *}$, and Wardah Abdul Razak ${ }^{1}$ \\ ${ }^{1}$ Department of Electrical \& Electronics Engineering, Universiti Pertahanan Nasional Malaysia, \\ 57000 Kuala Lumpur, Malaysia
}

\begin{abstract}
Nowadays ultra violet-visible (UV-Vis) spectrophotometers are widely used and is one of an important analytical instrument in modern day research. This work is conducted to determine oil quality discrimination of different selected oils using optical sensor, where the oil samples are analyzed within ultra violet (UV) spectrum, which ranges from 200nm to $400 \mathrm{~nm}$ wavelengths. The oils extracted from five plants are analyzed based on the light absorption rate at different wavelengths. Different energy value is required for electron transition from lower level to the higher, due to different molecular structure of the main compound in the oil. The highest absorption rate at wavelength $393 \mathrm{~nm}$ is achieved from lemongrass oil, whereas the lowest absorption peak at $368 \mathrm{~nm}$ is observed from ginger oil.
\end{abstract}

\section{Introduction}

There are a lot of methods to analyze oil quality based on the compound content of the oil such as high-performance liquid chromatography (HPLC) [1], nuclear magnetic resonance (NMR) [2] and other chemometric and conventional methods [3]. Over a certain range of wavelength, every chemical compound absorbs, transmits or reflects [4]. By using optical sensor, the quality of oil are obtained in which the oil sample is placed between a light source and sensor detector, and then intensity of a beam of light is measured before and after passing through the oil samples as shown in Fig. 1. In this work, light absorption rate is measured within UV spectrum, which ranges from $200 \mathrm{~nm}$ to $400 \mathrm{~nm}$.

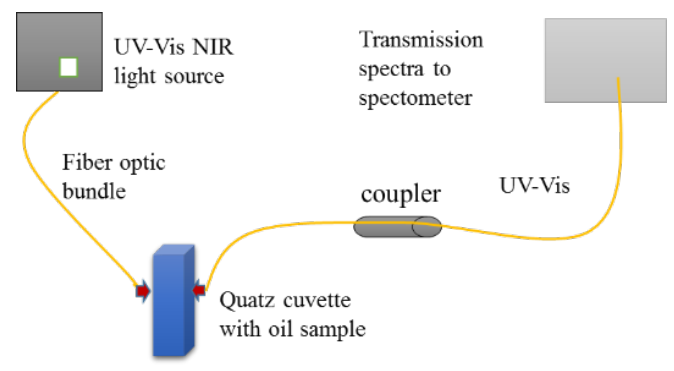

\footnotetext{
* Corresponding author: wardarazak@gmail.com
} 
Fig. 1. UV-Vis spectrophotometer

Different type of oils comprise of different group of hydrocarbon bonding. These combination of $\mathrm{H}$ and $\mathrm{C}$ bonding has different type of bonding such as sigma $(\sigma)$ bonding, pi $(\pi)$ bonding, non ( $y)$ lone pair bonding, $\pi^{*}$ anti-bonding and $\sigma^{*}$ anti-bonding [5]. In UV spectrophotometer only transition between pi bonding and non-bonding to anti bonding are occur because, the wavelength of that transition is in the range from $200 \mathrm{~nm}$ to $400 \mathrm{~nm}$. The great deal of energy required during the transition bonding. Each bonding has different energy level as show in Fig. 2.

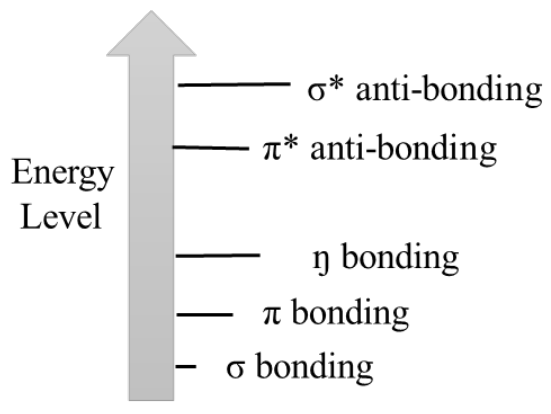

Fig. 2. Energy level of different types of bonding.

Energy is required in promoting the electron in molecules. The relationship between frequency of light absorbed and energy is

$$
E=h v
$$

where $E=$ energy of light $(\mathrm{J}), h=$ plank's constant $\left(6.62607004 \times 10^{-34} \mathrm{~m}^{2} \mathrm{~kg} / \mathrm{s}\right)$ and $v=$ frequency of light $(\mathrm{Hz})$. On the other hand, the relationship between wavelength and frequency is

$$
\lambda=c / f
$$

where $\lambda=$ wavelength $(\mathrm{m}), \mathrm{c}=$ speed of light $\left(3 \times 10^{8} \mathrm{~m} / \mathrm{s}\right)$ and $\mathrm{f}=$ frequency $(\mathrm{Hz})$ Therefore,

$$
E=h \mathrm{c} / \lambda
$$

Thus, it shows that the greater the energy jump the higher the frequency of light absorb and the lower the wavelength. During the experiment, the intensity of light is measured by using equation of transmittance, $T$

$$
T=I_{i} / I_{o}
$$

where, $I_{i}$ is the light intensity after the beam of light passes through the cuvette and $I_{o}$ is the light intensity before the beam of light passes through the cuvette as shown in Fig. 3. 
Fig. 3. The concept of transmittance, $T$.

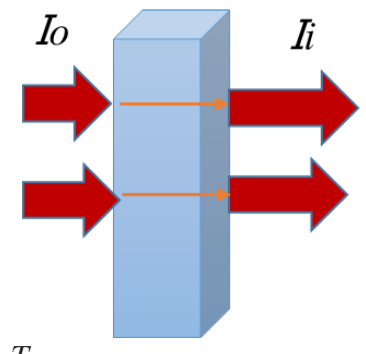

The absorption, $A$ and the transmittance, $T$ is related by

$$
A=-\log T
$$

where, absorbance is the amount of light that is absorbed by matter.

\section{Experimental Set up}

Five types of plant oils, derived from the plants which grow abundantly in South East Asia region, such as lemongrass, cinnamon, kaffir lime, ylang ylang and ginger are analyzed. The plants are chosen due to different medicinal properties [6]. Scientific names and main compound contents of the selected oils are tabulated in Table 1. The main compound contents are determined based on gas chromatography with mass spectrometry (GCMS) analysis.

Table 1. Scientific name and main compound content of the selected oils.

\begin{tabular}{|c|c|c|}
\hline Plant & Scientific name & Main compound \\
\hline Lemongrass & Cybopogon citratus DC [7] & Geranial \\
\hline $\begin{array}{c}\text { Cinnamon } \\
\text { bark }\end{array}$ & Cinnamomum verum [8] & Cinnamaldehyde \\
\hline Kaffir lime & Citrus hystrix [9] & Citronellol \\
\hline Ylang ylang & Cananga odorata [10] & Benzyl acetate \\
\hline Ginger & Zingiber officinale [11] & Curcumene \\
\hline
\end{tabular}

\section{Results \& Discussions}

The absorption spectrum of ginger, ylang ylang, cinnamon bark, kaffir lime leaves and lemongrass are shown in Fig. 4. Based on the spectrums, absortion rates at lower wavelengths are achieved from ginger and ylang ylang oils at $368 \mathrm{~nm}$ and $371 \mathrm{~nm}$ respectively, whereas absorption rates at higher wavelength are seen for cinnamon bark and kaffir lime leaves oils, which are observed at $392 \mathrm{~nm}$ respectively, and the absortion of lemongrass oils are seen at $393 \mathrm{~nm}$. More energy is required for light absortion at lower wavelength as in ginger and ylang ylang oils. 
Lower energy is required for electron transition in the compound with more stable conjugated system, thus causing maximum absorption peak at higher wavelength. Based on the results, lemongrass oil which contains geranial as the main compound, and comprises of more stable conjugated system causes maximum absorption peak at longer wavelength, $\lambda_{\max }$ of $393 \mathrm{~nm}$ compared to other oils. On the other hand, more energy is required for electron transition in the energy band, for zingiberine of ginger oil, therefore maximum absorption peak is only observed at shorter wavelength of $368 \mathrm{~nm}$.

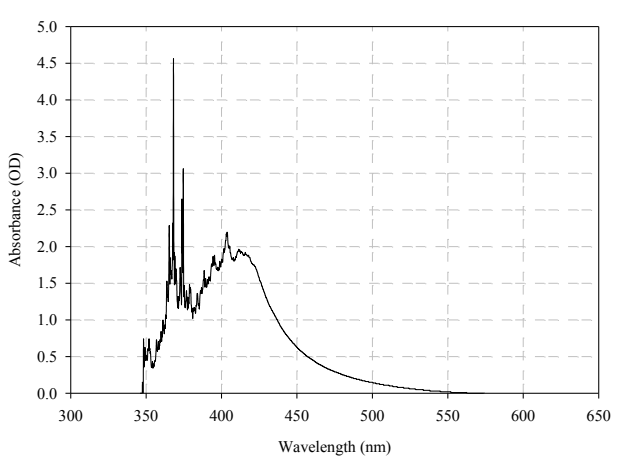

(a)

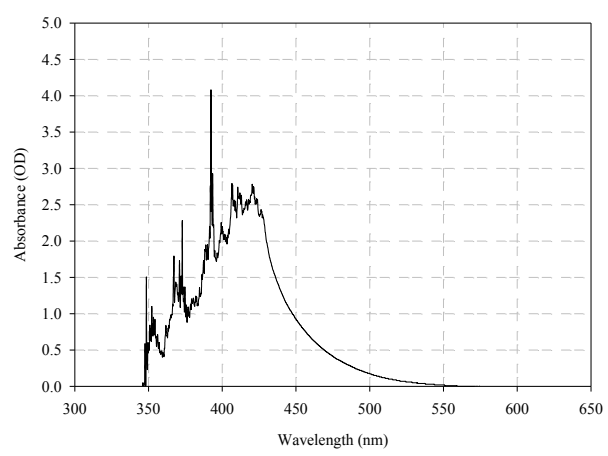

(c)

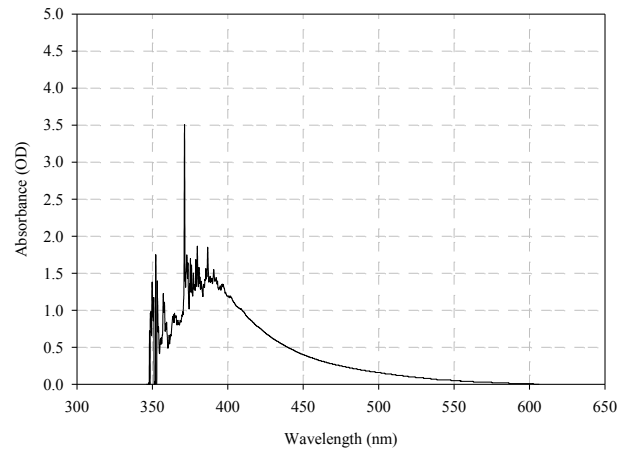

(b)

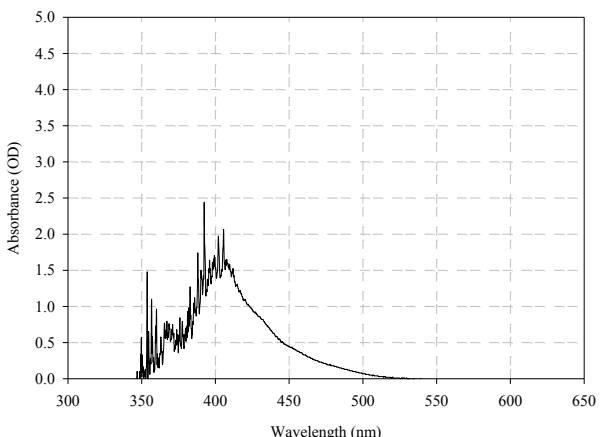

(d)

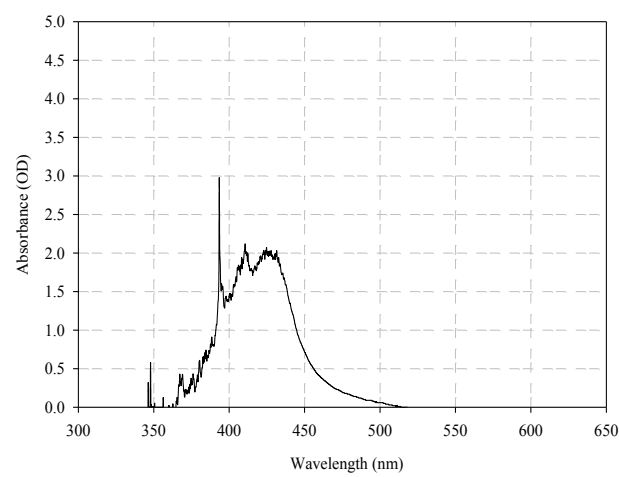

(e)

Fig. 4. Absorption spectrum of oils. (a) ginger (d) ylang ylang (c) cinnamon bark (d) kaffir lime leaves (e) lemongrass. 


\section{Conclusion}

Analysis on the absorption of light in five plant oils proves that absorbance rate is related to the energy required for electron transition from lower level to higher energy level. Oils with more stable molecular conjugated system requires lower energy for electron transition, causing light to be absorbed at longer wavelenth. In this work, lemongrass oil absorbed light at longer wavelength of $393 \mathrm{~nm}$, whereas ginger oil absorbed light at shorter wavelength of $368 \mathrm{~nm}$.

\section{References}

1. F. N. A. Rashid et al., "Aroma and optical absorption spectroscopy for quality assessment of vegetable cooking oils," 2014 2nd Int. Conf. Electron. Des. ICED 2014, pp. 339-342, 2011.

2. D. S. Lee, E. S. Lee, H. J. Kim, S. O. Kim, and K. Kim, "Reversed phase liquid chromatographic determination of triacylglycerol composition in sesame oils and the chemometric detection of adulteration," Anal. Chim. Acta, vol. 429, no. 2, pp. 321$330,2001$.

3. M. T. Kimometik, "(Determination of Commercials Cooking Oils and Fats Using Chemometrics," vol. 17, no. 1, pp. 146-152, 2013.

4. F. M. Sanda, M. E. Victor, T. A. Monica, and C. Alina, "Spectrophotometric Measurements Techniques Fermentation Process (Part One): Base Theory for Uv-Vis Spectrophotometric Measurements," Hungary-Romania Cross-Border Co-operation Program., p. 16, 2012.

5. Thermo Spectronic, "Basic UV-Vis Theory , Concepts and Applications Basic," ThermoSpectronic, pp. 1-28, 2013.

6. M. Shoeb, "Minireview Anticancer agents from medicinal plants," Bangladesh $J$ Pharmacol 2006; , vol. 1, pp. 35-41, 2006.

7. G. Lv, H. Yang, N. Xu, and A. M. Mouazen, "Identification of less-ripen, ripen, and over-ripen grapes during harvest time based on visible and near-infrared (Vis-NIR) spectroscopy," 2012 2nd Int. Conf. Consum. Electron. Commun. Networks, CECNet 2012 - Proc., vol. 4000, pp. 1067-1070, 2012.

8. B. Adinew, "GC-MS and FT-IR analysis of constituents of essential oil from Cinnamon bark growing in South-west of Ethiopia," vol. 1, no. 6, pp. 22-31, 2014.

9. C. Paper, "Supercritical Fluid Extraction and Gas Chromatographic-Mass Spectrometric Analysis of Terpenoids in Fresh Kaffir Lime Leaf Oil," vol. 40, no. 2, pp. 240-247, 2013.

10. Aromatics international Sdn Bhd, "Aromatics International: Aromatherapy Pure, Organic Essential Oils," aromatics international Sdn Bhd, - april 2015. [Online]. Available: https://www.aromatics.com/products/essential-oils?search=ylangylang. [Accessed 3 January 2017].

11. J. Kizhakkayil and B. Sasikumar, "Characterization of ginger ( Zingiber officinale Rosc .) germplasm based on volatile and non-volatile components," vol. 11, no. 4, pp. 777-786, 2012. 